\title{
Post-Transplant Cyclophosphamide in Hematopoietic Stem Cell Transplantation for Langerhans Cell Histiocytosis
}

\author{
Shunqiao Feng ${ }^{1}$, Lin Han ${ }^{2}$, Xiaodai Cui ${ }^{1}$, Junhui Li ${ }^{1}$, Zeliang Song ${ }^{1}$, Zhaoxia Zhang ${ }^{1}$, Xiaodong \\ Shi ${ }^{1}$ and Rong Liu ${ }^{1 *}$ \\ ${ }^{1}$ Department of Hematology, Capital Institute of Pediatrics, China \\ ${ }^{2}$ Department of Academic Research, Running Gene Inc, China
}

\begin{abstract}
Hematopoietic stem cell transplantation (HSCT) has the potential to cure refractory multisystem Langerhans cell histiocytosis (MS-LCH). However, a post-transplant cyclophosphamide (PTCy) regimen has never been applied for refractory MS-LCH. The objective of this article is to report the successful use of PTCy after reduced-intensity conditioning haploid HSCT in a 22-monthold girl with refractory MS-LCH and hemophagocytic lymphohistiocytosis (HLH). Her clinical symptoms were recurrent fever, polydipsia, diuresis, rash, and hepatosplenomegaly. She failed to respond to chemotherapy but was finally cured by haploid HSCT with PTCy regime. This case enriched our knowledge of the management of graft-versus-host disease prophylaxis in LCH patients, which has not been reported before.
\end{abstract}

KEYWORDS: Langerhans cell histiocytosis; Allogeneic haploid hematopoietic stem cell transplantation; Post-transplant cyclophosphamide

ABBREVIATIONS: HSCT: Hematopoietic Stem Cell Transplantation; MS-LCH: Multisystem Langerhans Cell Histiocytosis; PTCy: Post-Transplant Cyclophosphamide; HLH: Hemophagocytic Lymphohistiocytosis; LCH: Langerhans Cell Histiocytosis; SS: Single System; MS: Multiple System; GvHD: Graft versus Host Disease; CTX: Cyclophosphamide

\section{INTRODUCTION}

Langerhans cell histiocytosis (LCH) is a type of rare cancer that affects both adults and children. Infants are vulnerable to developing high-risk LCH [1]. The mortality rate of highrisk patients is relatively high, ranging from $10 \%$ to $66 \%$ [2-5]. Langerhans cells are a form of migratory skin dendritic cells that process and present antigen materials to the T cells of the immune system [6]. LCH patients have over-proliferation of Langerhanslike cells whose abnormal accumulation can be found in almost any of their organs, resulting in typical LCH lesions [7]. The clinical manifestations of LCH vary between individuals, from single-organ effects, such as a spontaneously healing isolated osteolytic lesion or red and scaly papules in skin folds, to life-threatening multiple organ failure, especially involving spleen and liver lesions $[8,9]$. Therapy for LCH is chosen depending on the severity of the disease. Local treatment with conventional chemotherapy can be applied for single-system (SS) LCH, which occurs in most patients [10]. However, some patients with multiple-system (MS) dysfunction and high-risk patients failed to respond to the initial and secondary therapies. Thus, hematopoietic stem cell transplantation (HSCT) is considered in several high-risk LCH patients, yielding improved outcomes and prognoses [11-14].

Graft-versus-host disease (GvHD) is a major complication that appears after allogeneic HSCT. Cyclophosphamide (CTX) is a chemotherapy drug that inhibits cell growth and is also commonly

\begin{tabular}{|c|c|}
\hline \multirow{2}{*}{ 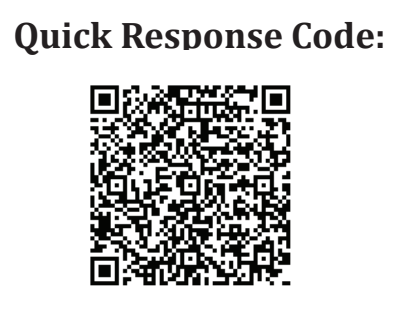 } & $\begin{array}{l}\text { Address for correspondence: Rong Liu, Capital Institute of Pediatrics, Department } \\
\text { of Hematology, Children's Hospital, Capital Institute of Pediatrics, China }\end{array}$ \\
\hline & $\begin{array}{l}\text { Received: July 15, } 2020 \quad \text { Published: September 2, } 2020 \\
\text { How to cite this article: Shunqiao F, Lin H, Xiaodai C, Junhui L, Zeliang S, Zhaoxia Z, Xiaodong } \\
\text { S, Rong L. Post-Transplant Cyclophosphamide in Hematopoietic Stem Cell Transplantation for } \\
\text { Langerhans Cell Histiocytosis. } 2020 \text { - 2(5) OAJBS.ID.000214. DOI: } 10.38125 / O A J B S .000214\end{array}$ \\
\hline
\end{tabular}


used to suppress the immune system and control post-transplant alloreactivity [15]. The application of CTX is established in the treatments of cancer and autoimmune diseases, and CTX is always used in myeloablative conditioning before transplantation, but a post-transplant cyclophosphamide (PTCy) regimen has never been applied for GvHD prophylaxis in LCH before.

Herein, we report our experience with a 22-month-old highrisk MS-LCH patient who was successfully treated with allogeneic haploid HSCT with CTX for GvHD prophylaxis. This case enriched our knowledge of the management of GvHD prophylaxis in LCH patients, which has not been considered or reported before.

\section{CASE REPORT}

The patient, a 22-month-old Chinese girl, was admitted to the Children's Hospital of Capital Institute of Pediatrics in 2015. Seven months before admission, she was administered antibiotics and treated with a blood component transfusion. These treatments relieved her fever and pancytopenia temporarily, but a recurrent fever remained. Examination of marrow cells revealed a significant neutrophil left shift, an increased number of cytoplasmic granules, failure of normal megakaryocyte production of blood thrombocytes, and hemophagocytosis. Four months before visiting our hospital, she had polydipsia and polyuria with nocturia.

In our hospital, physical examination revealed several dark brown skin eruptions present on her body and lymphadenectasis in the neck (1-2cm in diameter). A cardiopulmonary examination revealed normal results, but she had hepatosplenomegaly. On MRI images, the posterior pituitary gland was absent, and the pituitary stalk was interrupted. Bone scintigraphy revealed no abnormal reflective lesions. Immunohistochemical staining for Langerin, S100 and CD1a on a skin biopsy was strongly positive, but the staining for Kp-1 and CD163 was negative (Figure 1). BRAF staining showed moderate signals, and the Ki-67 signal displayed mild intensity and distribution ( $\pm 10 \%)$. A complete blood count showed a normal white blood cell count of $11.4 \times 10^{9} / \mathrm{L}\left(10-22 \times 10^{9} / \mathrm{L}\right)$, a hemoglobin level of $97 \mathrm{~g} / \mathrm{L}$ (reference $116-150 \mathrm{~g} / \mathrm{L}$ ) and a platelet count of $143 \times 10^{9} / \mathrm{L}$ $\left(157-371 \times 10^{9} / \mathrm{L}\right)$. The osmotic pressure was $288 \mathrm{m0sm} / \mathrm{kg}$ water (approximately $300 \mathrm{mOsm} / \mathrm{kg}$ ) in blood and $122 \mathrm{mOsm} / \mathrm{kg}$ water $(600-1000 \mathrm{mOsm} / \mathrm{kg})$ in urine. Her IL-2R level was $4700 \mathrm{IU} / \mathrm{ml}$ $(223-710 \mathrm{IU} / \mathrm{ml})$ and ferritin level was $29.77 \mathrm{ng} / \mathrm{ml}(35-55 \mathrm{ng} / \mathrm{ml})$. There were no abnormalities in thyroid gland function or natural killer cell activity. No Epstein-Barr virus-DNA or CytomegalovirusDNA was detected. PET-CT revealed several osteolytic lesions involving in the right parietal bone, bilateral temporal bones, the left acetabulum, and proximal femur (Figure 1). The patient was treated with multiple agent chemotherapy according to the JLSG96 protocol and DAL HX-83/90 protocol [5,16]. A second-line treatment regimen (cladribine and cytarabine) was applied as well [17]. However, the disease still developed progressively with recurrent fever, pancytopenia, and hepatosplenomegaly. During the treatment, the patient was diagnosed with HLH due to persistent fever, pancytopenia, hepatosplenomegaly, hypertriglyceridemia $3.33 \mathrm{mmol} / \mathrm{L}(0-1.69 \mathrm{mmol} / \mathrm{L})$, elevated ferritin level $>2000 \mathrm{ng} /$ $\mathrm{ml}(10-120 \mathrm{ng} / \mathrm{ml})$ and sCD25 8459-16618pg/ml $(<6400 \mathrm{pg} / \mathrm{ml})$, low natural killer cell activity 10.96\% (>=15.1\%), based on the diagnostic criteria of hemophagocytic lymphohistiocytosis (HLH). HLH-94 protocol was also used but failed to improve her symptoms.

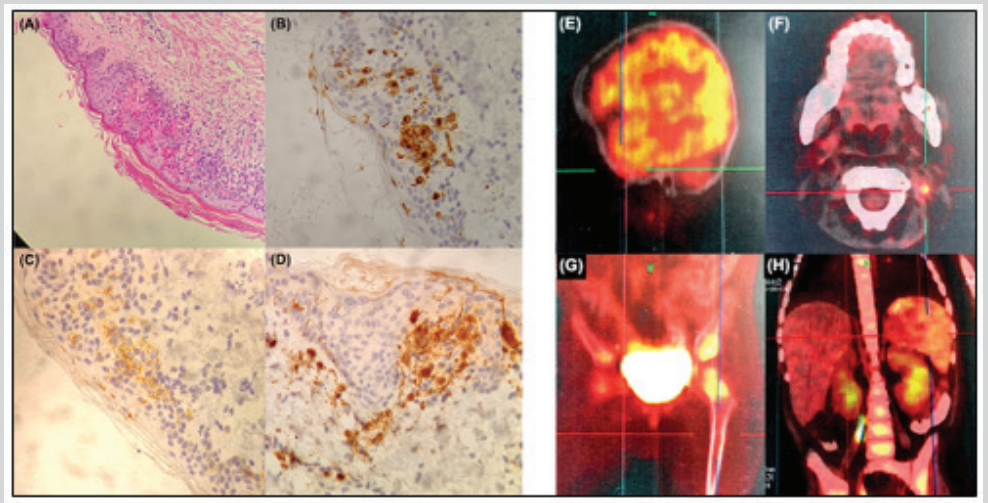

Figure 1: The immunohistochemical examination of skin biopsy and PET-CT images. (A) Hematoxylin and eosin (H\&E) staining on the patient's skin biopsy (x100). Immunohistochemistry revealed immunohistochemical markers including (B) langerin, (C) CDla and (D) S-100 protein. (E) Bone lesion in the left temporal bone with a high metabolic rate. (F) Enlargement of multiple lymph nodes in the bilateral neck with a metabolic focus. (G) Bone lesion in the left acetabulum and proximal femur with mild reflex uptake of the edge. $(\mathrm{H})$ Hepatosplenomegaly, indicating a high metabolic rate.

Due to the poor outcomes with conventional treatments, HSCT was performed as a salvage approach. Her father donated his compatible stem cells (blood type $\mathrm{B}+$ for $\mathrm{AB}+$ patient, halfmatched HLA). Before transplantation, busulfan $(1.2 \mathrm{mg} / \mathrm{kg}$, qid), etoposide $\left(300 \mathrm{mg} / \mathrm{m}^{2}, \mathrm{qd}\right)$ and fludarabine $\left(40 \mathrm{mg} / \mathrm{m}^{2}, \mathrm{qd}\right)$ were administered from days -8 to -6 , days -6 to -4 and days -5 to -2 , respectively (Figure 2). Bone marrow mononuclear cells $\left(25 \times 10^{8} /\right.$ $\mathrm{kg})$ and CD34+ cells $\left(14.8 \times 10^{6} / \mathrm{kg}\right)$ were transplanted through a peripheral blood infusion (day 0 ). Anti-thymocyte globulin $(2.5 \mathrm{mg} /$ $\mathrm{kg}$, qd) was administered for GvHD prophylaxis on days -6 and -5 followed by CTX $(50 \mathrm{mg} / \mathrm{kg}$, qd) administration from days +3 to +4 . From day +5 , mycophenolate mofetil $\left(500 \mathrm{mg} / \mathrm{m}^{2}\right.$, bid) and tacrolimus (up to 8-10ng/ml, i.v. then p.o.) were administered for a month and a year, respectively. After the CTX administration, the hepatosplenomegaly was relieved. On days +14 and +28 , full donor chimerism was present in the patient. However, the number of granulocytes remained lower than $0.5 \times 10^{8} / \mathrm{kg}$, and the platelet engraftment failed. This was considered a primary implantation dysfunction combined with cytomegaloviremia. On days +95 and +112 , invasive ventilator-assisted ventilation therapy was employed to relieve pneumonia with pulmonary hemorrhage and respiratory failure. Purified CD34+ cells were again infused into the patient on day +119 . Eleven days after the infusion (day +130$)$, platelet engraftment was achieved. The $20 \mathrm{ml} / \mathrm{kg}$ transfusions of 
platelets and red blood cells $(20 \mathrm{ml} / \mathrm{kg}$, up to $200 \mathrm{ml}$, every 4 or 5 days) were ceased. After allo-HSCT, the LCH and secondary HLH have been cured for three years. To date, the patient's diabetes insipidus has improved but is still under treatment.

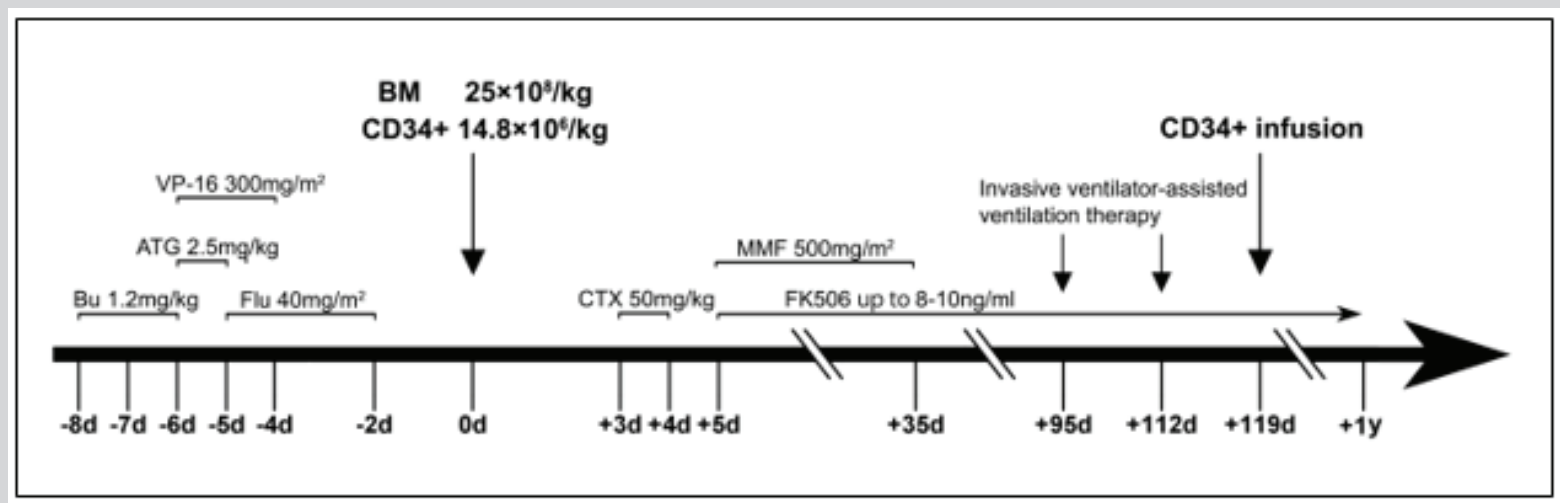

Figure 2: Medication administration and cell counts of the patient during transplantation. Busulfan (Bu, 1.2mg/kg, qid), etoposide (VP-16,300 mg/m², qd) and fludarabine (Flu, 40mg/m², qd) administration generated a reduced-

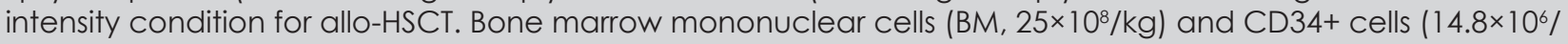
$\mathrm{kg}$ ) were transplanted through peripheral blood infusion. Anti-thymocyte globulin (ATG, $2.5 \mathrm{mg} / \mathrm{kg}$, qd) and cyclophosphamide (CTX, 50mg/kg, qd) were given for GvHD prophylaxis. Tacrolimus (FK506, up to 8-10ng/ml, i.v. then p.o.) and mycophenolate mofetil (MMF, $500 \mathrm{mg} / \mathrm{m}^{2}$, bid) were also administered every day from day +5 . Invasive ventilator-assisted ventilation therapy was employed on days +95 and +112 . CD34+ cells were infused to the patient on day +119 .

\section{DISCUSSION}

As a salvage strategy for refractory patients, HSCT is a wellestablished technique; however, the regimens of conditioning and GvHD prophylaxis are still controversial. To date, the high-risk of transplant-associated mortality attributed to high-intensity chemotherapy before transplantation has limited the wide application of these techniques in LCH patients $[8,18]$. Cooper has also stated that conventional myeloablation is not critical for LCH treatment and recommended reduced-intensity conditioning (RIC)-HSCT in patients with not only high-risk refractory LCH but also standard-risk LCH [19]. RIC-HSCT offers an alternative promising curative treatment with well-tolerated, decreased transplant-related mortality in LCH patients with a poor prognosis, even though a high-risk of relapse after RIC has been suggested [8,19-21]. Authors of previous research have also hypothesized the better overall survival rate might be attributed to better supportive care rather than to the increased use of a RIC regimen [21], but a RIC regimen indeed become more prevalent before transplantation.

Moreover, GvHD prophylaxis was a more critical procedure in our case because severe GvHD might have developed when the patient was treated by HLA half-matched HSCT and resulted in a poor outcome. High-dose post-transplant cyclophosphamide can selectively inactivate activated T cells. Hematopoietic stem cells are protected from large amounts of aldehyde dehydrogenase while retaining donor lymphocytes required for immune reconstitution and significantly reducing the incidence of GvHD [15,22-24]. Currently, the administration of CTX for GvHD prophylaxis performed well after half-matched transplantations in benign and malignant diseases but LCH $[25,26]$. Successful cures of refractory LCH with HSCT were usually followed by treatment with cyclosporine A (CyA) alone or CyA with methotrexate and daclizumab for GvHD prophylaxis [11-13,27,28]. Nevertheless, we reported a successful case in which a patient with refractory $\mathrm{LCH}$ was protected from GvHD by a PTCy regimen.

In our patient, since HSCT was employed in an active stage of the disease, with recurrent fever, hypercytokinemia and hepatosplenomegaly, the maximal suppression of the immune system was necessary during transplantation to mediate immune dysfunction. CTX, as a chemotherapeutic agent, could alleviate the fever and make the spleen retract during the conventional treatment, suggesting that it could successfully suppress the overactivated immune system. Therefore, this case suggests that the PTCy regimen might be more suitable for patients with an overactivated immune system.

\section{CONCLUSION}

This article reported the first successful use of PTCy for GvHD prophylaxis after RIC allogeneic haploidentical HSCT in a high-risk MS-LCH girl with secondary HLH and central diabetes insipidus. Although it is successful, this is the only one clinical case for now and we do not recommend it to be used as a safe treatment. However, the treatment indeed has the potentials to be an alternative treatment if the ultimate effectiveness of RIC-HSCT with PTCy regimen against refractory LCH can be determined with more cases.

\section{ACKNOWLEDGEMENT}

We appreciated the patient and her family for their participation in the study.

\section{CONFLICT OF INTEREST}

The author Lin Han is employed by Running Gene Inc. (Beijing, China). All authors declare that there is absent of any other commercial or financial relationships that could be considered as a potential conflict of interests.

\section{REFERENCES}

1. Sébastien H, Mathilde J, Guy L, Jean FE, Jean CA, et al. (2015) Vemurafenib use in an infant for high-risk langerhans cell histiocytosis. JAMA Oncol 1(6): 836-838.

2. Li D, H Li, Shi H (2017) [Clinical features and prognosis of langerhans cell histiocytosis in children: an analysis of 34 cases]. Zhongguo Dang Dai Er Ke Za Zhi 19(6): 627-631. 
3. Gadner H, Grois N, Arico M, Broadbent V, Ceci A, et al. (2001) A randomized trial of treatment for multisystem langerhans' cell histiocytosis. J Pediatr 138(5): 728-734.

4. Gadner H, Nicole G, Ulrike P, Milen M, Maurizio A, et al. (2008) Improved outcome in multisystem Langerhans cell histiocytosis is associated with therapy intensification. Blood 111(5): 2556-2562.

5. Minkov M, Nicole G, Andreas H, Ulrike P, Westermeier T, et al. (2002) Response to initial treatment of multisystem Langerhans cell histiocytosis: an important prognostic indicator. Med Pediatr Oncol 39(6): 581-585.

6. Collin M, Milne P (2016) Langerhans cell origin and regulation. Curr Opin Hematol 23(1): 28-35.

7. Makras P, Dimitrios P, George K, George P, Gregory AK, et al. (2005) Spontaneous gonadotrophin deficiency recovery in an adult patient with langerhans cell histiocytosis (LCH). Pituitary 8(2): 169-174.

8. Steiner M, Matthes MS, Attarbaschi A, Minkov M, Grois N, et al. (2005) Improved outcome of treatment-resistant high-risk Langerhans cell histiocytosis after allogeneic stem cell transplantation with reducedintensity conditioning. Bone Marrow Transplant 36(3): 215-225.

9. Grifo AH (2009) Langerhans cell histiocytosis in children. J Pediatr Oncol Nurs 26(1): 41-47.

10. Titgemeyer C, Grois N, Minkov M, Flucher WB, Gatterer MI, et al. (2001) Pattern and course of single-system disease in Langerhans cell histiocytosis data from the DAL-HX 83- and 90-study. Med Pediatr Oncol 37(2): 108-114.

11. Akkari V, Donadieu J, Piguet C, Bordigoni P, Michel G, et al. (2003) Hematopoietic stem cell transplantation in patients with severe Langerhans cell histiocytosis and hematological dysfunction: experience of the French Langerhans Cell Study Group. Bone Marrow Transplant 31(12): 1097-1103.

12. Vural K, Caglar C, Erol K, Vedat K, Canan A (2009) Hematopoietic stem cell transplantation in Langerhans cell histiocytosis: case report and review of the literature. Pediatr Transplant 13(3): 371-374.

13. Lai CC, Huang WC, Cheng SN (2008) Successful treatment of refractory langerhans cell histiocytosis by allogeneic peripheral blood stem cell transplantation. Pediatr Transplant 12(1): 99-104.

14. Kudo K, Ohga S, Morimoto A, Ishida Y, Suzuki N, et al. (2010) Improved outcome of refractory Langerhans cell histiocytosis in children with hematopoietic stem cell transplantation in Japan. Bone Marrow Transplant 45(5): 901-906

15. Ahlmann M, Hempel G (2016) The effect of cyclophosphamide on the immune system: implications for clinical cancer therapy. Cancer Chemother Pharmacol 78(4): 661-671.

16. Morimoto A, Satoshi I, Naoko K, Eiichi I, Urara K et al. (2006) Improved outcome in the treatment of pediatric multifocal Langerhans cel histiocytosis: Results from the Japan Langerhans Cell Histiocytosis Study Group-96 protocol study. Cancer 107(3): 613-619.

17. Donadieu J, Frederic B, Max VN, Mohamed B, Odile B, et al. (2015) Cladribine and cytarabine in refractory multisystem Langerhans cell histiocytosis: results of an international phase 2 study. Blood 126(12): 1415-1423.

18. Hatakeyama N, Tsukasa H, Masaki Y, Natsuko I, Yoko H, et al. (2010) Successful treatment of refractory langerhans cell histiocytosis with pulmonary aspergillosis by reduced-intensity conditioning cord blood transplantation. Pediatr Transplant 14(3): E4-10

19. Cooper N, Rao K, Goulden N, Webb D, Amrolia P, et al. (2008) The use of reduced-intensity stem cell transplantation in haemophagocytic lymphohistiocytosis and langerhans cell histiocytosis. Bone Marrow Transplantation 42(Suppl 2): S47-50.

20. Schmid C, Myriam L, Arnon N, Dietger N, Luca C, et al. (2012) Treatment, risk factors, and outcome of adults with relapsed AML after reduced intensity conditioning for allogeneic stem cell transplantation. Blood 119(6): 1599-1606.

21. Veys PA, Vasanta N, Scott KB, Wensheng H, Giuseppe B, et al. (2015) Haematopoietic stem cell transplantation for refractory Langerhans cell histiocytosis: outcome by intensity of conditioning. Br J Haematol 169(5): 711-718

22. Luznik L, Ephraim JF (2010) High-dose, post-transplantation cyclophosphamide to promote graft-host tolerance after allogeneic hematopoietic stem cell transplantation. Immunol Res 47(1-3): 65-77.

23. Fuchs EJ (2015) HLA-haploidentical blood or marrow transplantation with high-dose, post-transplantation cyclophosphamide. Bone Marrow Transplant 50(Suppl 2): S31-36.

24. Luznik L, Paul VOD, Ephraim JF (2012) Post-transplantation cyclophosphamide for tolerance induction in HLA-haploidentical bone marrow transplantation. Semin Oncol 39(6): 683-693.

25. Peter D, Anna S, Kwang WA, Mary E, Carlos L, et al. (2019) PTCy-based haploidentical vs matched related or unrelated donor reduced-intensity conditioning transplant for DLBCL. Blood Adv 3(3): 360-369.

26. Junichi S, Naomi K, Tomoaki F, Kazuhiko K, Shuichi O, et al. (2015) HLA-Haploidentical Peripheral Blood Stem Cell Transplantation with Post-Transplant Cyclophosphamide after Busulfan-Containing ReducedIntensity Conditioning. Biol Blood Marrow Transplant 21(9): 16461652

27. Oscar GL, José CJP, Olga CR, Consuelo MG, Homero GA, et al. (2008) Allogeneic hematopoietic stem cell transplantation using a reducedintensity conditioning regimen in infants: experience at a single institution in Mexico. Pediatr Hematol Oncol 25(1): 39-47.

28. Yang J, Qin MQ, Wang B, Zhu GH, Zhang L, et al. (2014) Haploidentical parental hematopoietic stem cell transplantation in pediatric refractory Langerhans cell histiocytosis. Pediatr Transplant 18(4): E124-129. 